\title{
Calibration of Quartz-Enhanced Photoacoustic Sensors for Real-Life Adaptation
}

\author{
Jesper B. Christensen (D), David Balslev-Harder, Lars Nielsen $\mathbb{D}^{D}$, Jan C. Petersen and Mikael Lassen * \\ Danish Fundamental Metrology, Kogle Allé 5, 2970 Hørsholm, Denmark; jbc@dfm.dk (J.B.C.); \\ dbh@dfm.dk (D.B.-H.); $\operatorname{ln@dfm.dk~(L.N.);~jcp@dfm.dk~(J.C.P.)~}$ \\ * Correspondence: ml@dfm.dk
}

check for

updates

Citation: Christensen, J.B.;

Balslev-Harder, D.; Nielsen, L.;

Petersen, J.C.; Lassen, M. Calibration of Quartz-Enhanced Photoacoustic Sensor for Real-Life Adaptation. Molecules 2021, 26, 609. https:// doi.org/10.3390/molecules26030609

Academic Editor: Cristina Achim Received: 8 December 2020 Accepted: 19 January 2021 Published: 25 January 2021

Publisher's Note: MDPI stays neutral with regard to jurisdictional clai$\mathrm{ms}$ in published maps and institutional affiliations.

Copyright: (C) 2021 by the authors. Licensee MDPI, Basel, Switzerland. This article is an open access article distributed under the terms and conditions of the Creative Commons Attribution (CC BY) license (https:// creativecommons.org/licenses/by/ $4.0 /)$.

\begin{abstract}
We report on the use of quartz-enhanced photoacoustic spectroscopy for continuous carbondioxide measurements in humid air over a period of six days. The presence of water molecules alters the relaxation rate of the target molecules and thus the amplitude of the photoacoustic signal. Prior to the measurements, the photoacoustic sensor system was pre-calibrated using $\mathrm{CO}_{2}$ mole fractions in the range of $0-10^{-3}(0-1000 \mathrm{ppm})$ and at different relative humidities between $0 \%$ and $45 \%$, while assuming a model hypothesis that allowed the photoacoustic signal to be perturbed linearly by $\mathrm{H}_{2} \mathrm{O}$ content. This calibration technique was compared against an alternative learning-based method, where sensor data from the first two days of the six-day period were used for self-calibration. A commercial non-dispersive infrared sensor was used as a $\mathrm{CO}_{2}$ reference sensor and provided the benchmark for the two calibration procedures. In our case, the self-calibrated method proved to be both more accurate and precise.
\end{abstract}

Keywords: photoacoustics; gas spectroscopy; environmental sensors; carbon dioxide; humidity; optics; lasers; metrology; calibration

\section{Introduction}

The photoacoustic spectroscopy (PAS) technique is finding increasing interest as a powerful, yet simple, trace-gas detection method [1-7]. PAS, however, is not an absolute metrological technique, and its use requires detailed knowledge of the chemical composition of the investigated gas sample. This renders photoacoustic (PA) sensors difficult to calibrate, and therefore commercialize, for environmental monitoring applications [8].

The PAS method is different from other optical absorption-based methods, most notably the tunable diode laser absorption spectroscopy (TDLAS), cavity ring-down spectroscopy, and non-dispersive infrared absorption spectroscopy (NDIR) [9-15]. Whereas these methods directly measure optical attenuation, PAS is based on the detection of acoustic waves generated by exciting ro-vibrational states of target molecules with modulated light [16-18]. The absorbed energy translates into kinetic energy, which forms an acoustic wave that can be detected with a pressure transducer. In a simplistic view, the generated PA sound-wave intensity depends linearly (in the low-absorption regime) on the concentration of the target molecule and a spectral overlap between the molecular absorption cross section and the light spectrum. However, from a more general perspective, the generated PA sound-wave intensity depends not only on the concentration of the target molecule, but on the entire gas-sample composition. Other molecules may alter the relaxation kinetics of the various excited ro-vibrational modes $[19,20]$, causing a change in the PA signal strength. In this way, the measured PA signal is gas-matrix dependent, meaning that PA-based trace-gas sensors, while they can be extremely sensitive, can quickly become inaccurate without adequate calibration of the necessary gas-matrix corrections. Most notably, and highly relevant for real-life adaptation of PA sensors, the presence of water vapor in a gas sample acts as an enzyme of the relaxation process, and thereby enhances, or in fewer cases diminishes, the generated sound wave. In practice, this entails that absolute 
environmental gas-concentration measurements can only be achieved upon correction of the sample water content.

Multiple strategies and methods have so far been implemented for humidity correction of PA trace-gas sensors [21-29]. Here, we develop a calibration framework based on a simple learning-based method for quantifying the influence of humidity on photoacoustic carbon-dioxide concentration measurements. Using this approach, the model is only required to be locally accurate (within the observed values), which is a highly relaxed

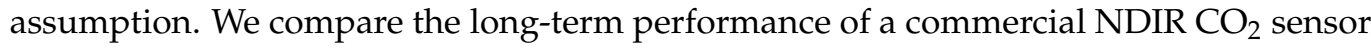
with that of a quartz-enhanced photoacoustic (QEPAS) module (for details on the QEPAS technique, see, e.g., [30-32]) resonantly pumped by a pulsed optical parametric oscillator (OPO) having an emission wavelength of $4.32 \mu \mathrm{m}$. We find very good agreement with the NDIR sensor when calibrated using atmospheric measurement data as training data for the calibration algorithm.

\section{Experimental Setup}

The experimental setup, sketched in Figure 1, includes a mid-infrared (MIR) pulsed optical parametric oscillator (OPO), a QEPAS sensor module (ADM01, Thorlabs, Dachau, Germany), an NDIR sensor (T6613, Telaire, Telaire Pforzheim, Germany), optical detectors for power measurement, humidity/temperature/pressure sensors, a mass-flow control system, and a Raspberry PI microprocessor for data acquisition.

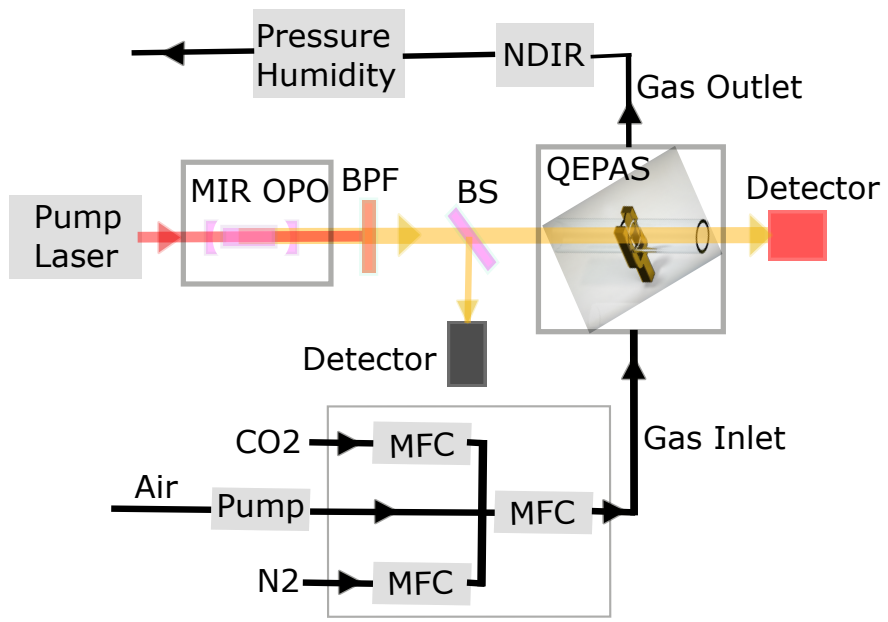

Figure 1. Block diagram of the main parts of the experimental setup. QEPAS: Quartz-enhanced PAS. MIR OPO: Mid-infrared (MIR) pulsed optical parametric oscillator. MFC: Mass-flow controller. BPF: Bandpass filter. BS: Beamsplitter. Two detectors (black: fast detector; red: thermal detector) are monitoring the optical power.

The light source is based on an actively Q-switched nanosecond Nd:YAG pump laser (BrightSolution, Anchorage, AK, USA), which emits pulses with a duration of $15 \mathrm{~ns}$ at a repetition rate of $12.457 \mathrm{kHz}$ and a center wavelength of $1064 \mathrm{~nm}$. The near-infrared pulses are focused into a $40 \mathrm{~mm}$ long fan-out structured periodically poled lithium niobate crystal (HC Photonics, HsinChu City, Taiwan) placed inside a $55 \mathrm{~mm}$ long linear cavity with a waist of approximately $150 \mu \mathrm{m}$ at the cavity midpoint. The two cavity mirrors are characterized by having radius-of-curvature of $100 \mathrm{~mm}$ and a high reflectance $(R>0.99)$ in the spectral region from $1350 \mathrm{~nm}$ to $1700 \mathrm{~nm}$. Exploiting the resonant signal enhancement in this wavelength range, a continuous chirp of the nonlinear crystal facilitates efficient generation of MIR pulsed light from $2.8 \mu \mathrm{m}$ to $4.5 \mu \mathrm{m}$. In this work, the MIR wavelength is fixed to $4.32 \mu \mathrm{m}$ and with $15 \mathrm{~mW}$ of mean optical output power, matching ro-vibrational lines in the P-branch of the asymmetric stretchband of $\mathrm{CO}_{2}$. More details on the MIR OPO can be found in [33]. 
The QEPAS module contains a quartz tuning fork (QTF) with an eigenfrequency of $f_{0}=12,457 \mathrm{~Hz}$ and a quality factor of $\sim 5300 \pm 50$ at 1 atm [34]. The QTF is piezo-electrically active in the mechanical mode for which the two prongs oscillate 180 degrees out of phase (asymmetrical stretching mode), and is therefore sensitive to a pressure wave originating from in between the two prongs and less sensitive to external sound waves which makes the two prongs oscillate in-phase [30,31]. Acoustic coupling is further improved by two microresonator tubes each having a length of $12.4 \mathrm{~mm}$ [1]. In- and outcoupling of the mid-infrared light through the module happens through two $\mathrm{BaF}_{2}$ windows with a combined transmittance of $\sim 0.9$. QEPAS is a powerful technique and has shown the capability to monitor gas concentrations at the part per billion or even part per trillion levels [30,31,35-38].

The gas-flow control is realized using a triplet of Brooks 0254 mass-flow controllers (MFCs). Two MFCs are used for setting the in-flow rate of $\mathrm{N}_{2}$ and 1000-ppm $\mathrm{CO}_{2}$ in an $\mathrm{N}_{2}$ matrix. The $\mathrm{N}_{2}-\mathrm{CO}_{2}$ gas flow is combined with a valve-controlled inlet that enables suction of laboratory air into the tube system using a mini vacuum pump with variable flow rate. The combined gas flow is led through the third MFC, which is used to monitor and log the total gas flow, and on to the QEPAS module and the NDIR sensor.

Data processing is enabled by two lock-in amplifiers receiving the electrical local oscillator signal from the active laser Q-switch and with integration times of $300 \mu \mathrm{s}$. The first lock-in amplifier measures the incident optical power just before the QEPAS module, and the second lock-in amplifier demodulates the PA output signal of the QEPAS' in-build transimpedance amplifier using a 1-f configuration (i.e., amplitude modulation) [39,40]. The output from the lock-in amplifiers are digitized using a 10-bit ADC (MCP3008) and logged using a Raspberry PI 3 module (RPI). The same RPI simultaneously logs data from the NDIR sensor and a humidity-temperature-pressure sensor (BME280, Adafruit, New York, NY, USA).

\section{Theory}

A PA sensor can in the simple case be mathematically modeled by assuming a PA signal that depends linearly on both the target-molecule concentration and the optical power used for probing the gas sample. However, for gas samples with a non-zero watervapor concentration of $c_{\mathrm{H}_{2} \mathrm{O}}$, the PA signal can be significantly altered. Considering the PA measurement of $\mathrm{CO}_{2}$ concentration, the PA voltage signal, $U_{\mathrm{PA}}$, may therefore be described by a relation of the form

$$
U_{\mathrm{PA}}=\alpha_{1} c_{\mathrm{CO}_{2}}\left(1+\operatorname{Poly}_{n>0}\left(c_{\mathrm{H}_{2} \mathrm{O}}\right)\right) P
$$

wherein $P$ is the optical power, $\alpha_{1}$ is related to the optical absorption of $\mathrm{CO}_{2}$ at the employed wavelength, and Poly ${ }_{n>0}\left(c_{\mathrm{H}_{2} \mathrm{O}}\right)$ is a constant-excluding polynomial with respect to $c_{\mathrm{H}_{2} \mathrm{O}}$. To test and compare our calibration method with related published work, the PA signal is hypothesized to be perturbed linearly by water content [24,25], i.e., $\operatorname{Poly}_{n}\left(\mathrm{c}_{\mathrm{H}_{2} \mathrm{O}}\right)=\alpha_{\mathrm{AH} \mathrm{C}_{2} \mathrm{O}}$. This reforms Equation (1) to

$$
\bar{U}_{\mathrm{PA}}=\alpha_{1} c_{\mathrm{CO}_{2}}\left(1+\alpha_{\mathrm{AH}^{c} \mathrm{H}_{2} \mathrm{O}}\right) \text {. }
$$

The power-normalized PA signal is defined as $\bar{U}_{\mathrm{PA}} \equiv U_{\mathrm{PA}} / U_{\mathrm{P}}$, whereof $U_{\mathrm{P}}$ is the power-logged voltage signal. Using $U_{P}$, rather than the actual optical power, results in an arbitrary scaling of $\alpha_{1}$ of $\alpha_{1} \rightarrow \alpha_{P} \alpha_{1}$, where $\alpha_{P}=\left(\partial P / \partial U_{P}\right)$ is the power-to-voltage linear coefficient of the power meter. 


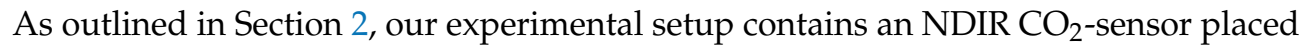
in series with the PA module. The NDIR module is based on differential optical absorption at $\lambda \approx 4.3 \mu \mathrm{m}$, and is practically unaffected by water concentration [15]. The NDIR output is highly linear with respect to $\mathrm{CO}_{2}$ concentration, i.e., $c_{\mathrm{CO}_{2}} \sim a_{\mathrm{NDIR}} U_{\mathrm{NDIR}}+b_{\mathrm{NDIR}}$, as is confirmed below. This allows the NDIR module to function as a $\mathrm{CO}_{2}$ reference. Insertion of the linear NDIR response into Equation (2) yields the relationship between PA output and NDIR output, given as

$$
\bar{U}_{\mathrm{PA}}=a_{0}+a_{1} U_{\mathrm{NDIR}}+a_{2} U_{\mathrm{NDIR}} c_{\mathrm{H}_{2} \mathrm{O}}+a_{3} c_{\mathrm{H}_{2} \mathrm{O}}
$$

where the coefficients $a_{0}=b_{\mathrm{NDIR}} \alpha_{1}, a_{1}=a_{\mathrm{NDIR}} \alpha_{1}, a_{2}=a_{\mathrm{NDIR}} \alpha_{1} \alpha_{\mathrm{AH}}$, and $a_{3}=b_{\mathrm{NDIR}} \alpha_{1} \alpha_{\mathrm{AH}}$.

Equation (3) provides a model function with which the PA sensor can be calibrated with reference to the NDIR sensor for varying carbon-dioxide and water concentrations. The water-vapor concentration is computed based on the BME280 output (relative humidity, pressure, and temperature), and is expressed as [41]

$$
c_{\mathrm{H}_{2} \mathrm{O}}=\frac{P x_{\mathrm{H}_{2} \mathrm{O}}}{R T}=\frac{611.6 \mathrm{~Pa}}{R T} \exp \left[\frac{17.48(T-273.15 \mathrm{~K})}{T-32.42 \mathrm{~K}}\right] \mathrm{RH} \text {, }
$$

where $x_{\mathrm{H}_{2} \mathrm{O}}$ is the molar fraction of water vapor, $R \equiv 8.314462618 \mathrm{~J} \mathrm{~mol}^{-1} \mathrm{~K}^{-1}$, RH is the relative humidity expressed as a fractional number between 0 and 1, $T$ is the absolute temperature measured in kelvin, and $P$ is the pressure in pascal. The calculated watervapor concentration is associated with a standard uncertainty calculated using the laws of error propagation while using the rated uncertainties of the sensor of $u(T)=1 \mathrm{~K}$, $u(\mathrm{RH})=3 \%$, and $u(P)=100 \mathrm{~Pa}$.

\section{Experiments}

\subsection{Calibration of Carbon-Dioxide Sensors (Dry)}

We first assess the $\mathrm{CO}_{2}$-response of the two sensors in dry conditions, i.e., $x_{\mathrm{H}_{2} \mathrm{O}}=0$. To this end, the lab-air valve is closed off, and the MFCs are used to achieve different $\mathrm{CO}_{2}$ concentrations (in $N_{2}$ ). The $\mathrm{CO}_{2}$ concentration is varied from 0 to $10^{-3}$ in steps of $\sim 125$ ppm while preserving a constant flow rate of $80 \mathrm{~mL} / \mathrm{min}$. For each $\mathrm{CO}_{2}$-level, measurements are conducted for $200 \mathrm{~s}$ resulting in 100 and 50 measurement points for the QEPAS and NDIR sensors, respectively. With the expectancy of a linear relationship between $\mathrm{CO}_{2}$ concentration and output signal, a linear regression is performed on the flow- and power-normalized data, see Figure 2. The NDIR sensor calibration curve Figure $2 \mathrm{a}$, which displays linear behaviour over the entire measurement range, is given by $U_{\mathrm{NDIR}}=\beta_{\mathrm{NDIR}}+\alpha_{\mathrm{NDIR}} c_{\mathrm{CO}_{2}}=440.73 \mathrm{mV}+0.0324 \mathrm{mV} \mathrm{m}^{3} \mathrm{~mol}^{-1}{ }^{1} \mathrm{CO}_{2}$ with parameter uncertainties of $u\left(\alpha_{\mathrm{NDIR}}\right)=5 \times 10^{-5} \mathrm{mV} \mathrm{m}^{3} \mathrm{~mol}^{-1}, u\left(\beta_{\mathrm{NDIR}}\right)=1.09 \mathrm{mV}$ and a correlation of $r\left(\alpha_{\text {NDIR }}, \beta_{\text {NDIR }}\right)=-0.85$. The QEPAS sensor Figure $2 \mathrm{~b}$ is seen to be affected by saturation effects at high $\mathrm{CO}_{2}$ concentration [42]. As a result, only points for which $x_{\mathrm{CO}_{2}}<600 \mathrm{ppm}$ are included in the linear regression analysis. The resulting fit

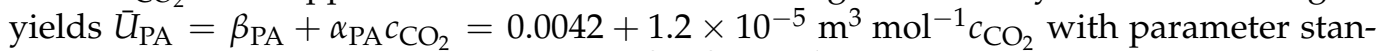
dard uncertainties of $u\left(\alpha_{\mathrm{PA}}\right)=2 \times 10^{-8} \mathrm{~m}^{3} \mathrm{~mol}^{-1}, u\left(\beta_{\mathrm{PA}}\right)=0.0003$ and correlation $r\left(\alpha_{\mathrm{PA}}, \beta_{\mathrm{PA}}\right)=-0.83$. 

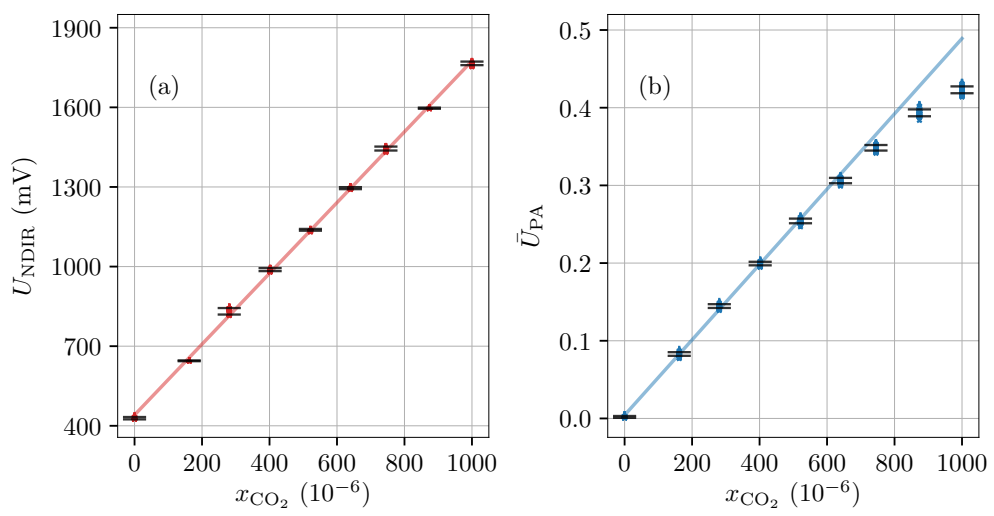

Figure 2. Calibration of carbon-dioxide sensor response in dry nitrogen gas samples. (a) NDIR sensor response, and (b) power-normalized QEPAS sensor response. The error bars ( $y$-direction) identify the $1 \sigma$ variation of datapoints around the mean value of each dataset. During the calibration procedure, the pressure and temperature were $P=(1012 \pm 1) \mathrm{hPa}$ and $T=(22.8 \pm 0.1){ }^{\circ} \mathrm{C}$, respectively.

\subsection{Calibration of Carbon-Dioxide Sensors (Wet)}

With the purpose of using the PA sensor for atmospheric $\mathrm{CO}_{2}$ monitoring, it is now calibrated to correct for humidity content in the sample gas. This is achieved by using the water-independent, and highly linear, response of the NDIR sensor, as a $\mathrm{CO}_{2}$ reference. Two approaches for calibration are attempted and assessed: (i) the PA response is measured for a range of $\mathrm{CO}_{2}$ and humidity levels and the data are fitted to Equation (3) using appropriate constraints, and (ii) the natural variations in atmospheric $\mathrm{CO}_{2}$ and water content over a period of three days are used as a basis for establishing a relationship between PA signal, humidity level, and $\mathrm{CO}_{2}$ concentration, in a learning-like fashion (see Section 4.3).

Our statistical analysis is based on a least-squares approach, described in [43], which is in compliance with the "Guide to the Expression of Uncertainty in Measurement" (GUM) [44]. In this framework, each measurand $\left(\bar{U}_{\mathrm{PA}}^{(i)}, U_{\mathrm{NDIR}^{\prime}}^{(i)} c_{\mathrm{H}_{2} \mathrm{O}}^{(i)}\right)$ is considered a statistical estimate (with accompanying uncertainty) of the "true" values $\left(\zeta_{\mathrm{PA}}^{(i)}, \zeta_{\mathrm{NDIR}}^{(i)}, \zeta_{\mathrm{H}_{2} \mathrm{O}}^{(i)}\right)$. Each set of measurands are linked through implicit constraints, which, according to Equation (3), are given by

$$
a_{0}+a_{1} \zeta_{\mathrm{NDIR}}^{(i)}+a_{2} \zeta_{\mathrm{NDIR}}^{(i)} \zeta_{\mathrm{H}_{2} \mathrm{O}}^{(i)}+a_{3} \zeta_{\mathrm{H}_{2} \mathrm{O}}^{(i)}-\zeta_{\mathrm{PA}}^{(i)}=0, \quad \forall i .
$$

The general least-squares algorithm provides values for the model parameters, $a_{0-3}$, refined estimates of the measurands $\left(\zeta_{\mathrm{PA}^{\prime}}^{(i)} \zeta_{\mathrm{NDIR}}^{(i)} \zeta_{\mathrm{H}_{2} \mathrm{O}}^{(i)}\right)$, and the covariance matrix of all determined quantities.

Figure 3a demonstrates how the presence of water molecules enhances the PA signal for a specific $\mathrm{CO}_{2}$-level (quantified by the NDIR sensor response). The data are constituted by four different data series differentiated by the approximate mole fraction of water of 0 (blue), $2 \times 10^{-3}$ (green), $4 \times 10^{-3}$ (orange), and atmospheric levels of $10 \times 10^{-3}$ to $12 \times 10^{-3}$ (red). Linear trendlines are added to the plot for the three dataseries (with sub-atmospheric humidity levels) to help visualization of the slightly increased slope as a function of humidity level, and the error bars signify standard uncertainties found through repeated measurements.

Running the general least-squares algorithm using the data shown in Figure 3a, provides parameter estimates of $a_{0}, a_{1}, a_{2}$ and $a_{3}$ with which the model residuals $\left(\bar{U}_{\mathrm{PA}}^{(i)}-\zeta_{\mathrm{PA}}^{(i)}\right)$ provides a basis for a validity check using a $\chi^{2}$-test. Figure $3 \mathrm{~b}$ shows the normalized devia- 
tions (residuals) between the PA measurands $\bar{U}_{\mathrm{PA}}^{(i)}$ and the refined estimates $\zeta_{\mathrm{PA}}^{(i)}$ defined as [43]

$$
d_{i}=\frac{\bar{U}_{\mathrm{PA}}^{(i)}-\zeta_{\mathrm{PA}}^{(i)}}{u\left(\bar{U}_{\mathrm{PA}}^{(i)}-\zeta_{\mathrm{PA}}^{(i)}\right)}
$$

and further displays the $\chi^{2}$-value obtained in the fit. With a value of $\chi^{2}=40.3>30=v$, where $v$ is the degrees of freedom, $\operatorname{Pr}\left(\chi^{2}(30)>40.3\right)=0.098$, meaning that the model (null) hypothesis is rejected at a 10\%-significance level, but can not be discarded at a $5 \%$ significance level. However, the observed $\chi^{2}$-value indicates that the model might be too simple to describe the physics at hand in both dry and wet conditions simultaneously. This conclusion is strengthened by the normalized deviations, a considerable amount of which lie outside (or close to the boundaries) of the range $[-2 ; 2]$.
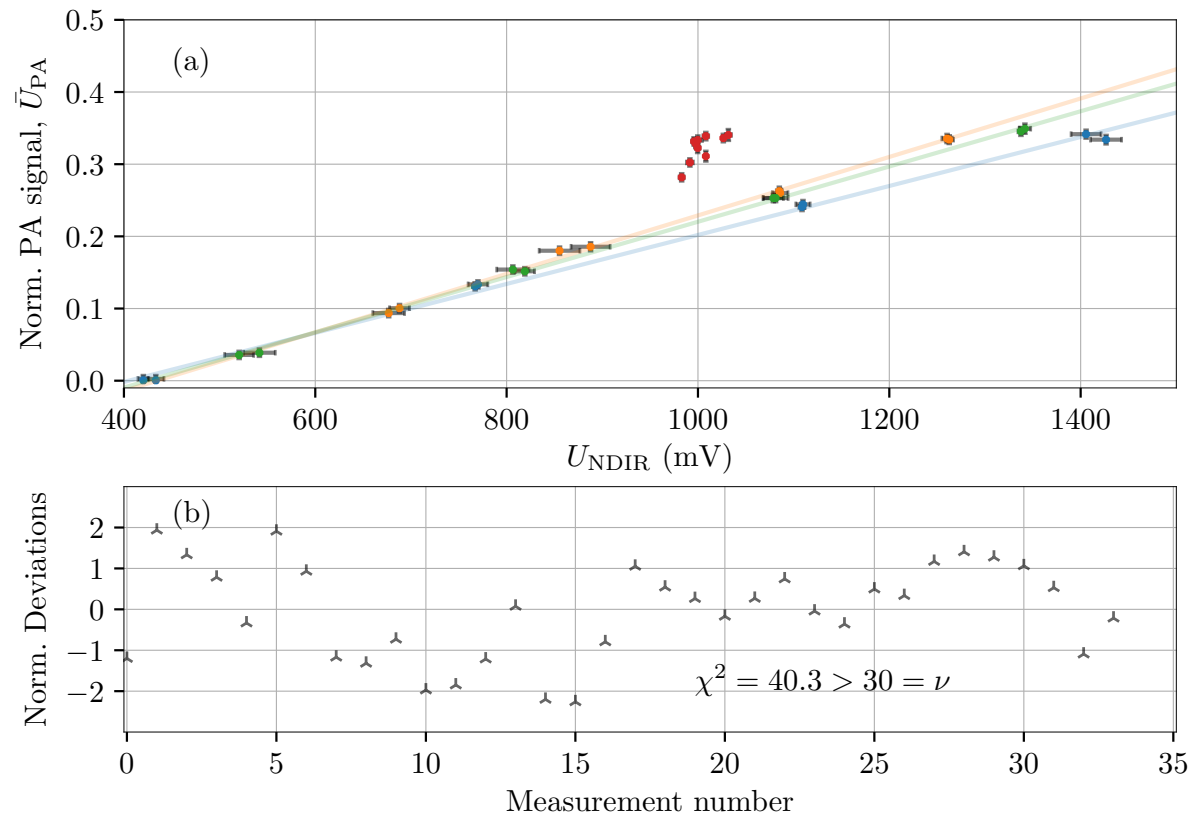

Figure 3. Calibration of a PA sensor of $\mathrm{CO}_{2}$ in humid gas samples. (a) acquired PA signal for a wide range of $\mathrm{CO}_{2}$ - and absolute humidity levels, demonstrating the PA water-enhancement effect. The error bars represent $1 \sigma$ standard deviations for each measurement point; (b) the normalized deviations, $d_{i}$ for each of the 34 measurand sets, acquired using the generalized least-squares algorithm [43].

\subsection{Prolonged Atmospheric Carbon-Dioxide Measurements}

We now assess the PA sensor with respect to stability in performance over prolonged periods of multiple days. For a given set of measurands $\left(\bar{U}_{\mathrm{PA}}, c_{\mathrm{H}_{2} \mathrm{O}}\right)$, we predict a $\mathrm{CO}_{2}-$ concentration of

$$
c_{\mathrm{CO}_{2}}=b_{\mathrm{NDIR}}+a_{\mathrm{NDIR}} \frac{\bar{U}_{\mathrm{PA}}-\left(a_{0}+a_{3} c_{\mathrm{H}_{2} \mathrm{O}}\right)}{a_{1}+a_{2} c_{\mathrm{H}_{2} \mathrm{O}}} .
$$

The combined model and measurand uncertainty of this prediction is quantified by the variance

$$
u^{2}\left(c_{\mathrm{CO}_{2}}\right)=d^{T} \Sigma d,
$$

where $d$ is a column vector containing the partial derivatives of $c_{\mathrm{CO}_{2}}$ with respect to parameters $a_{0-3}, b_{\mathrm{NDIR}}, a_{\mathrm{NDIR}}$, and the measurands $\bar{U}_{\mathrm{PA}}$ and $c_{\mathrm{H}_{2} \mathrm{O}}$, and $\Sigma$ is the associated eight-dimensional covariance matrix of those same quantities.

Figure 4 illustrates our 6-day long $\mathrm{CO}_{2}$ measurements using both the NDIR sensor and the estimated concentration levels based on three different methods of calculation. Figure $4 \mathrm{~b}$ compares the NDIR signal with a $\mathrm{CO}_{2}$-measured PA signal uncorrected for the atmospheric water content visualized in Figure $4 \mathrm{a}$ for reference. In this case, the $\mathrm{CO}_{2}$ 
concentration is calculated based on a "dry" calibration (Figure 2), and thus fails to take into account the enhancing effect of the water molecules. As a result, the deduced $\mathrm{CO}_{2}$ data shows strong correlation to the humidity data, and significantly overestimates the $\mathrm{CO}_{2}$ content of the gas. Conversely, Figure $4 \mathrm{c}$ shows the estimated $\mathrm{CO}_{2}$ concentration based on the calibration procedure described in Section 4.2. In this situation, the bias offset of the PA-calculated $\mathrm{CO}_{2}$-level is largely removed; however, the water content is still visually observable, indicating that the humidity is not ideally compensated with the computed calibration parameters. Finally, Figure $4 \mathrm{~d}$ shows the case where the system is allowed to self-calibrate based on "historical" data. The grey area marks the training period, in which data from the three sensors are used to build a model in the same way as outlined in Section 4.2. Using this latter approach, the model in Equation (2) is only required to be locally accurate (within the observed values of $\mathrm{CO}_{2}$ and $\mathrm{H}_{2} \mathrm{O}$ ), which is a highly relaxed assumption. As a result, the PA-calculated $\mathrm{CO}_{2}$ level succeeds in predicting the same $\mathrm{CO}_{2}$ level as the reference NDIR sensor. Different sets of calibration parameters for different levels of humidity could in principle be determined and used to calibrate the PA sensor for all humidity values.

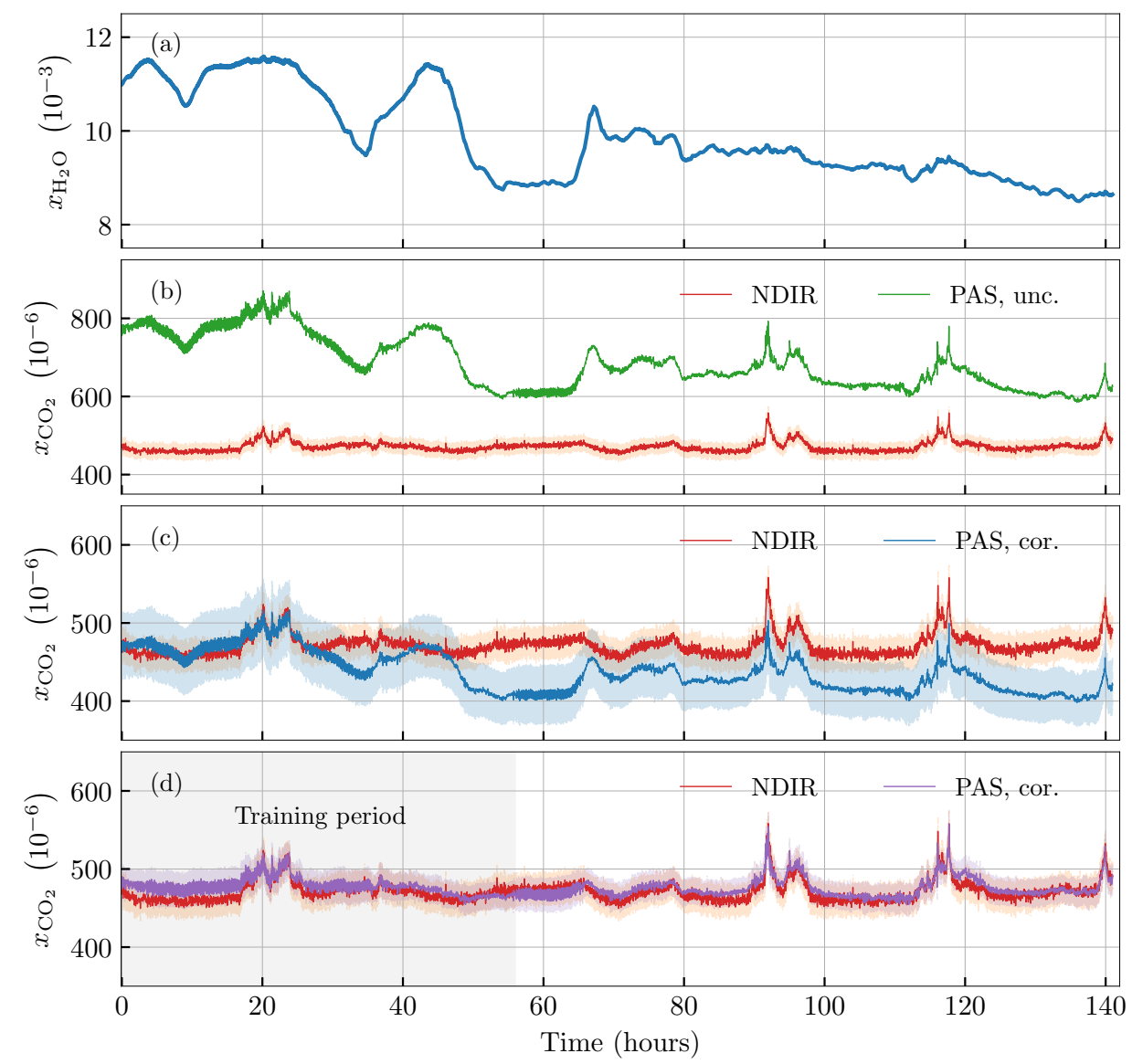

Figure 4. Carbon-dioxide monitoring over six days in atmospheric humidity levels. (a) measured absolute humidity; (b) $\mathrm{CO}_{2}$ level deduced from PA signal, uncorrected for the atmospheric water content; (c) $\mathrm{CO}_{2}$ level deduced from PA signal, corrected for the atmospheric water content using parameters from the calibration (Figure 3); (d) $\mathrm{CO}_{2}$ level deduced from PA signal, corrected for the atmospheric water content using a model based on "historical" training data from the shaded time period. The shaded regions around each curve represent the calculated $1 \sigma$ confidence region for each time series.

\section{Discussion}

Measurements of gas concentrations using PAS becomes highly nontrivial in wet (water-containing) gas mixtures. Although water molecules do not, necessarily, directly 
contribute through optical absorption, they influence the relaxation mechanisms of other absorbing molecules in the mixture. This effect is apparent from Figure $4 \mathrm{~b}$, in which the PA signal is seen to be enhanced by more than a factor of 1.5 as a result of the humidity levels $\left(x_{\mathrm{H}_{2} \mathrm{O}} \sim 10 \times 10^{-3}\right)$ displayed above in Figure $4 \mathrm{a}$. This enhancement has previously been demonstrated to be both gas- and wavelength dependent, but, perhaps more critically, the enhancement factor does not necessarily seem to be a simple linear function of absolute humidity (see fx [28] for a study on CO). This lag of linearity can also be found in our data for $\mathrm{CO}_{2}$, e.g., by comparing data at time stamps $t=15 \mathrm{~h}$ and $t=60 \mathrm{~h}$, for which we estimate water-enhancement factors, $\alpha_{\mathrm{AH}}$ of $(0.0015 \pm 0.0002) \mathrm{m}^{3} \mathrm{~mol}^{-1}$ and $(0.0008 \pm 0.0002) \mathrm{m}^{3} \mathrm{~mol}^{-1}$, respectively. It is this inconsistency that results in the inaccurate correction performed in Figure $4 c$, and which ultimately means that the model hypothesis must be discarded as being too simple to describe the physics at hand.

To investigate if the established setup could still be used for $\mathrm{CO}_{2}$ monitoring, we attempted to base the calibration on "historical" data from the PA sensor, the humidity sensor, and the NDIR sensor as a $\mathrm{CO}_{2}$ reference. After two days of model training in normal atmospheric conditions, our PA sensor proved to be capable of estimating the same $\mathrm{CO}_{2}$ level (within the uncertainties) as the reference NDIR sensor throughout a period of four days. This also included the final tests of daylong human interference seen towards the end of the considered time span that lasted from the 5th to the 10th of November 2020.

Our analysis here involved the use of a cheap miniature sensor for monitoring the atmospheric humidity. Such sensors are typically fairly inaccurate from an absolute perspective, resulting in the large confidence interval in Figure 4c, and a smaller relative uncertainty leading to the smaller confidence interval in Figure $4 \mathrm{~d}$. However, even in the latter case, the humidity uncertainty is still the largest contribution in the final uncertainty budget of the photoacoustically-based $\mathrm{CO}_{2}$ measurements. This strongly underlines that PA-based concentration measurements in real-life monitoring conditions necessarily involve a highly sensitive measurement of the absolute humidity level. A sensitive humidity measurement can either be done using the PA effect [25], or, perhaps more conveniently, by embedding small state-of-the-art humidity sensors (see e.g., $[45,46])$ into the PA gas chamber.

\section{Conclusions}

In this work, we presented a pilot study of quartz-enhanced photoacoustic carbondioxide measurements in air of varying humidity. With our general least-squares statistical framework, we tested a model function for which the water-concentration was assumed to perturb the photoacoustic signal to first order. However, the calibration, and subsequent prolonged carbon-dioxide measurements, resulted in a rejection of the model hypothesis. Instead, the photoacoustic sensor was calibrated using atmospheric measurement data from the first two days, of a six-day period, as training data. Upon this calibration, the photoacoustic sensor was found to provide carbon-dioxide estimates that were in agreement with the reference non-dispersive infrared module over the entire test period.

Author Contributions: Methodology, J.B.C., L.N., and M.L.; software, D.B.-H. and J.B.C.; validation, J.B.C. and M.L.; formal analysis, J.B.C., L.N., and M.L.; investigation, J.B.C. and M.L.; resources, J.C.P.; data curation, J.B.C. and M.L.; writing-original draft preparation, J.B.C. and M.L.; writing-review and editing, D.B.-H., J.B.C., J.C.P., L.N., M.L.; visualization, J.B.C. and M.L.; supervision, M.L.; project administration, J.C.P.; funding acquisition, J.C.P., M.L. All authors have read and agreed to the published version of the manuscript.

Funding: This work is funded by the Innovation Fund Denmark (IFD) under File No. 8158-00003B and the Danish Agency for Institutions and Educational Grants.

Data Availability Statement: The data presented in this study are available on request from the corresponding author.

Conflicts of Interest: The authors declare no conflict of interest. 
Sample Availability: The data leading to the results of this work are available from the authors upon reasonable requests.

\begin{tabular}{|c|c|}
\hline \multicolumn{2}{|c|}{ Abbreviations } \\
\hline$T$ & ng abbreviations are used in this manuscript: \\
\hline $\mathrm{AH}$ & Absolute humidity \\
\hline MFC & Mass-flow controller \\
\hline MIR & Midinfrared \\
\hline NDIR & Non-dispersive infrared \\
\hline $\mathrm{OPO}$ & Optical parametric oscillator \\
\hline PA & Photoacoustic \\
\hline PAS & Photoacoustic spectroscopy \\
\hline QEPAS & Quartz-enhanced photoacoustic spectroscopy \\
\hline QTF & Quartz tuning fork \\
\hline TDLAS & Tunable diode Laser absorption spectroscopy \\
\hline
\end{tabular}

\section{References}

1. Miklós, A.; Hess, P.; Bozóki, Z. Application of acoustic resonators in photoacoustic trace gas analysis and metrology. Rev. Sci. Instrum. 2001, 72, 1937-1955. [CrossRef]

2. Spagnolo, V.; Patimisco, P.; Pennetta, R.; Sampaolo, A.; Scamarcio, G.; Vitiello, M.S.; Tittel, F.K. THz Quartz-enhanced photoacoustic sensor for $\mathrm{H}_{2} \mathrm{~S}$ trace gas detection. Opt. Express 2015, 23, 7574-7582. [CrossRef] [PubMed]

3. Ma, Y. Review of recent advances in QEPAS-based trace gas sensing. Appl. Sci. 2018, 8, 1822. [CrossRef]

4. Palzer, S. Photoacoustic-Based Gas Sensing: A Review. Sensors 2020, 20, 2745. [CrossRef]

5. Sampaolo, A.; Menduni, G.; Patimisco, P.; Giglio, M.; Passaro, V.M.; Dong, L.; Wu, H.; Tittel, F.K.; Spagnolo, V. Quartz-enhanced photoacoustic spectroscopy for hydrocarbon trace gas detection and petroleum exploration. Fuel 2020, 277, 118118. [CrossRef]

6. Tomberg, T.; Vainio, M.; Hieta, T.; Halonen, L. Sub-parts-per-trillion level sensitivity in trace gas detection by cantilever-enhanced photo-acoustic spectroscopy. Sci. Rep. 2018, 8, 1848. [CrossRef]

7. Popa, C. Ethylene Measurements from Sweet Fruits Flowers Using Photoacoustic Spectroscopy. Molecules 2019, $24,1144$. [CrossRef]

8. Zifarelli, A.; Giglio, M.; Menduni, G.; Sampaolo, A.; Patimisco, P.; Passaro, V.M.N.; Wu, H.; Dong, L.; Spagnolo, V. Partial Least-Squares Regression as a Tool to Retrieve Gas Concentrations in Mixtures Detected Using Quartz-Enhanced Photoacoustic Spectroscopy. Anal. Chem. 2020, 92, 11035-11043. [CrossRef]

9. Lackner, M. Tunable diode laser absorption spectroscopy (TDLAS) in the process industries-A review. Rev. Chem. Eng. 2007, 23, 65-147. [CrossRef]

10. Jongma, R.T.; Boogaarts, M.G.; Holleman, I.; Meijer, G. Trace gas detection with cavity ring down spectroscopy. Rev. Sci. Instrum. 1995, 66, 2821-2828. [CrossRef]

11. Werle, P.; Slemr, F.; Maurer, K.; Kormann, R.; Mücke, R.; Jänker, B. Near- and mid-infrared laser-optical sensors for gas analysis. Opt. Lasers Eng. 2002, 37, 101-114 [CrossRef]

12. Bogue, R. Detecting gases with light: A review of optical gas sensor technologies. Sens. Rev. 2015, 35, 133-140. [CrossRef]

13. Hodgkinson, J.; Tatam, R.P. Optical gas sensing: A review. Meas. Sci. Technol. 2013, 24, 012004. [CrossRef]

14. Amann, A.; Poupart, G.; Telser, S.; Ledochowski, M.; Schmid, A.; Mechtcheriakov, S. Applications of breath gas analysis in medicine. Int. J. Mass Spectrom. 2004, 239, 227-233. [CrossRef]

15. Dinh, T.V.; Choi, I.Y.; Son, Y.S.; Kim, J.C. A review on non-dispersive infrared gas sensors: Improvement of sensor detection limit and interference correction. Sens. Actuators B Chem. 2016, 231, 529-538. [CrossRef]

16. Tam, A.C. Applications of photoacoustic sensing techniques. Rev. Mod. Phys. 1986, 58, 381-431. [CrossRef]

17. Manohar, S.; Razansky, D. Photoacoustics: A historical review. Adv. Opt. Photonic 2016, 8, 586-617. [CrossRef]

18. Lassen, M.; Brusch, A.; Balslev-Harder, D.; Petersen, J.C. Phase-sensitive noise suppression in a photoacoustic sensor based on acoustic circular membrane modes. Appl. Opt. 2015, 54, D38-D42. [CrossRef]

19. Rooth, R.A.; Verhage, A.J.L.; Wouters, L.W. Photoacoustic measurement of ammonia in the atmosphere: Influence of water vapor and carbon dioxide. Appl. Opt. 1990, 29, 3643-3653. [CrossRef]

20. Lang, B.; Breitegger, P.; Brunnhofer, G.; Valero, J.P.; Schweighart, S.; Klug, A.; Hassler, W.; Bergmann, A. Molecular relaxation effects on vibrational water vapor photoacoustic spectroscopy in air. Appl. Phys. B 2020, 126, 1-18. [CrossRef]

21. Wysocki, G.; Kosterev, A.A.; Tittel, F.K. Influence of molecular relaxation dynamics on quartz-enhanced photoacoustic detection of $\mathrm{CO}_{2}$ at $\lambda=2 \mu \mathrm{m}$. Appl. Phys. B 2006, 85, 301-306. [CrossRef]

22. Kosterev, A.A.; Bakhirkin, Y.A.; Tittel, F.K.; McWhorter, S.; Ashcraft, B. QEPAS methane sensor performance for humidified gases. Appl. Phys. B 2008, 92, 103-109. [CrossRef]

23. Ma, Y.; Lewicki, R.; Razeghi, M.; Tittel, F.K. QEPAS based ppb-level detection of CO and $\mathrm{N}_{2} \mathrm{O}$ using a high power CW DFB-QCL. Opt. Express 2013, 21, 1008. [CrossRef] [PubMed] 
24. Yin, X.; Dong, L.; Zheng, H.; Liu, X.; Wu, H.; Yang, Y.; Ma, W.; Zhang, L.; Yin, W.; Xiao, L.; et al. Impact of humidity on quartz-enhanced photoacoustic spectroscopy based CO detection using a near-IR telecommunication diode laser. Sensors 2016, 16, 162. [CrossRef] [PubMed]

25. Elefante, A.; Menduni, G.; Rossmadl, H.; Mackowiak, V.; Giglio, M.; Sampaolo, A.; Patimisco, P.; Passaro, V.; Spagnolo, V. Environmental Monitoring of Methane with Quartz-Enhanced Photoacoustic Spectroscopy Exploiting an Electronic Hygrometer to Compensate the $\mathrm{H}_{2} \mathrm{O}$ Influence on the Sensor Signal. Sensors 2020, 20, 2935. [CrossRef] [PubMed]

26. Elefante, A.; Giglio, M.; Sampaolo, A.; Menduni, G.; Patimisco, P.; Passaro, V.; Wu, H.; Rossmadl, H.; Mackowiak, V.; Cable, A.; et al. Dual-gas quartz-enhanced photoacoustic sensor for simultaneous detection of methane/nitrous oxide and water vapor. Anal. Chem. 2019, 91, 12866-12873. [CrossRef]

27. Wu, H.; Dong, L.; Yin, X.; Sampaolo, A.; Patimisco, P.; Ma, W.; Zhang, L.; Yin, W.; Xiao, L.; Spagnolo, V.; et al. Atmospheric CH 4 measurement near a landfill using an ICL-based QEPAS sensor with V-T relaxation self-calibration. Sens. Actuators B Chem. 2019, 297, 126753. [CrossRef]

28. Hayden, J.; Baumgartner, B.; Lendl, B. Anomalous Humidity Dependence in Photoacoustic Spectroscopy of CO Explained by Kinetic Cooling. Appl. Sci. 2020, 10, 843. [CrossRef]

29. Li, Y.; Wang, R.; Tittel, F.K.; Ma, Y. Sensitive methane detection based on quartz-enhanced photoacoustic spectroscopy with a high-power diode laser and wavelet filtering. Opt. Lasers Eng. 2020, 132, 106155. [CrossRef]

30. Kosterev, A.A.; Bakhirkin, Y.A.; Curl, R.F.; Tittel, F.K. Quartz-enhanced photoacoustic spectroscopy. Opt. Lett. 2002, $27,1902-1904$. [CrossRef]

31. Patimisco, P.; Sampaolo, A.; Dong, L.L.; Tittel, F.K.; Spagnolo, V. Recent advances in quartz enhanced photoacoustic sensing. Appl. Phys. Rev. 2018, 5, 011106. [CrossRef]

32. Ma, Y.; Qiao, S.; Patimisco, P.; Sampaolo, A.; Wang, Y.; Tittel, F.K.; Spagnolo, V. In-plane quartz-enhanced photoacoustic spectroscopy. Appl. Phys. Lett. 2020, 116, 061101. [CrossRef]

33. Christensen, J.B.; Høgstedt, L.; Friis, S.M.M.; Lai, J.-Y.; Chou, M.-H.; Balslev-Harder, D.; Petersen, J.C.; Lassen, M. Intrinsic spectral resolution limitations of QEPAS sensors for fast and broad wavelength tuning. Sensors 2020, 20, 4725. [CrossRef] [PubMed]

34. Friedt, J.M.; Carry, E. Introduction to the quartz tuning fork. Am. J. Phys. 2007, 75, 415-422. [CrossRef]

35. Patimisco, P.; Scamarcio, G.; Tittel, F.K.; Spagnolo, V. Quartz-Enhanced Photoacoustic Spectroscopy: A Review. Sensors 2014, 14, 6165-6206. [CrossRef] [PubMed]

36. Spagnolo, V.; Patimisco, P.; Borri, S.; Scamarcio, G.; Bernacki, B.E.; Kriesel, J. Part-per-trillion level SF 6 detection using a quartz enhanced photoacoustic spectroscopy-based sensor with single-mode fiber-coupled quantum cascade laser excitation. Opt. Lett. 2012, 37, 4461-4463. [CrossRef]

37. Lassen, M.; Lamard, L.; Feng, Y.; Peremans, A.; Petersen, J.C. Off-axis quartz-enhanced photoacoustic spectroscopy using a pulsed nanosecond mid-infrared optical parametric oscillator. Opt. Lett. 2016, 41, 4118-4121. [CrossRef]

38. Petra, N.; Zweck, J.; Kosterev, A.A.; Minkoff, S.E.; Thomazy, D. Theoretical analysis of a quartz-enhanced photoacoustic spectroscopy sensor. Appl. Phys. B 2009, 94, 673-680. [CrossRef]

39. Lassen, M.; Baslev-Harder, D.; Brusch, A.; Nielsen, O.S.; Heikens, D.; Persijn, S.; Petersen, J.C. Photo-acoustic sensor for detection of oil contamination in compressed air systems. Opt. Express 2017, 25, 1806-1814. [CrossRef]

40. Lamard, L.; Balslev-Harder, D.; Peremans, A.; Petersen, J.C.; Lassen, M. Versatile photoacoustic spectrometer based on a mid-infrared pulsed optical parametric oscillator. Appl. Opt. 2019, 58, 250-256. [CrossRef]

41. Vaisala, O. Humidity Conversion Formulas B210973EN-F; Helsinki: Vaisala, Finland, 2013.

42. Hayden, J.; Baumgartner, B.; Waclawek, J.P.; Lendl, B. Mid-infrared sensing of CO at saturated absorption conditions using intracavity quartz-enhanced photoacoustic spectroscopy. Appl. Phys. B 2019, 125, 159. [CrossRef] [PubMed]

43. Nielsen, L. Evaluation of measurements by the method of least squares. In Algorithms Approx, 4th ed.; Levesley, J., Andreson, I.J., Mason, J.C., Eds.; University of Huddersfield: Huddersfield, UK, 2002; pp. 170-186.

44. BIPM; IEC; IFCC; ISO; IUPAC; IUPAP; OIML. Guide to the Expression of Uncertainty in Measurement; ISO: Geneva, Switzerland, 1995.

45. Wang, X.; Ding, B.; Yu, J.; Wang, M.; Pan, F. A highly sensitive humidity sensor based on a nanofibrous membrane coated quartz crystal microbalance. Nanotechnology 2009, 21, 055502. [CrossRef] [PubMed]

46. Cheng, B.; Tian, B.; Xie, C.; Xiao, Y.; Lei, S. Highly sensitive humidity sensor based on amorphous $\mathrm{Al}_{2} \mathrm{O}_{3}$ nanotubes. J. Mater. Chem. 2011, 21, 1907-1912. [CrossRef] 